\title{
Rote Linien für aufdringliche Patienten
}

\author{
Dieser Ausgabe von MMW liegt wieder „info praxisteam“ bei, das Magazin für Medizinische \\ Fachangestellte. Thema in Heft 4/15 sind Patienten, die die Mitarbeiterinnen nerven oder sogar \\ bedrängen. Hier müssen Sie Ihr Team unterstützen und klar Grenzen aufzeigen.
}

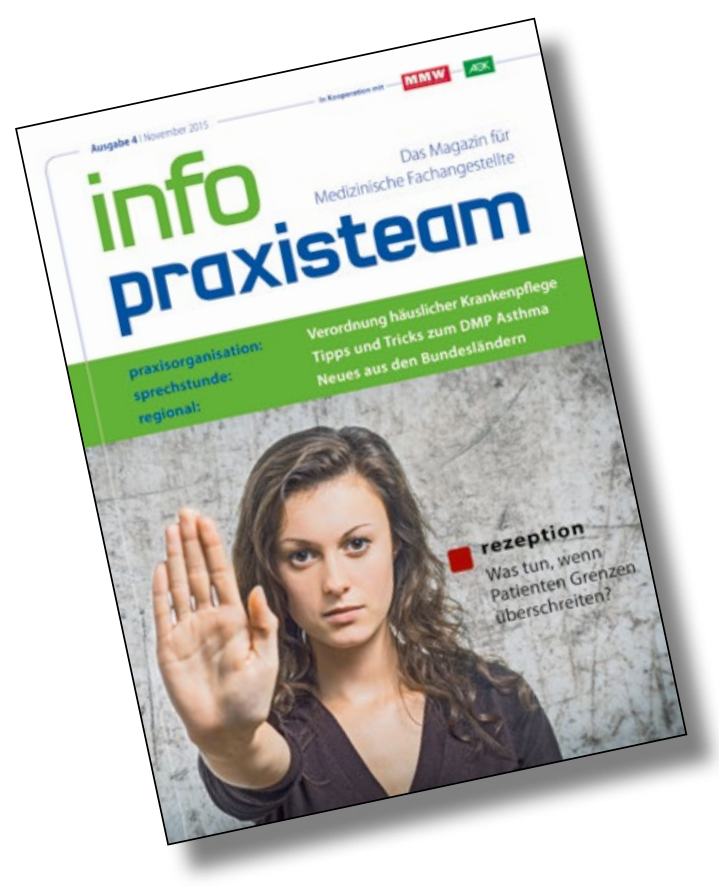

_ Jede MFA kennt die Situation, dass ein Patient ihr „auf die Pelle rückt“. Das kann in Form einer zweideutigen Bemerkung passieren („Sie sehen aber heute wieder knackig aus!"), aber auch, indem der aufdringliche Patient tatsächlich räumlich zu nahe kommt. Manche Menschen verletzen die gesellschaftlich akzeptierten Distanzzonen, etwa indem sie die Mitarbeiterin am Arm berühren oder sich direkt vor ihr aufbauen.

Eine solch ungewollte Nähe empfinden wir als höchst unangenehm. Eine klassische Situation an der Rezeption: Ein Patient möchte nicht im Wartezimmer Platz nehmen, sondern bleibt im Eingangsbereich stehen, verwickelt die MFA in ein endloses Gespräch oder folgt ihr sogar durch die Praxis, etwa auf dem Weg ins Labor.

Solches Verhalten kann keinesfalls toleriert werden. Doch wie reagiert man am besten? Die Mitarbeiterinnen sollten sich nicht von der Unruhe oder Aggres- sion anstecken lassen, aber auch nicht gute Miene zum bösen Spiel machen, wenn sie die Situation als unangenehm empfinden. Berührungen z. B. können unterbunden werden, indem der Patient freundlich, aber bestimmt auf einen größeren Abstand geschoben wird.

\section{Verbal klare Grenzen ziehen}

Dazu gibt man ihm klar zu verstehen, dass er Grenzen verletzt: „Herr Müller, ich möchte nicht, dass Sie mich anfassen. Danke für Ihr Verständnis.“ Danach führt man das Gespräch professionell und unaufgeregt weiter. Eine eindeutige Körpersprache kann den Inhalt der Worte unterstreichen.

Wenn ein Patient die gebotene Dis$\tan z$ vermissen lässt, sollte das Praxisteam versuchen herauszufinden, ob er tatsächlich dreist und aufdringlich ist oder ob das Verhalten andere Gründe hat. Menschen im Vollbesitz ihrer emotionalen und geistigen Fähigkeiten haben sich an Regeln zu halten, auch in der Praxis. Bei manchen Patienten aber gehört die fehlende Distanz zu einem Krankheitsbild.

Patienten mit psychischer Erkrankung sind oft in besonderer Weise schutzbedürftig. Regelverstöße durch Kinder tolerieren wir meistens in einem weit größeren Ausmaß, als wir es bei Erwachsenen jemals tun würden. Psychisch Kranke befinden sich mitunter in einem Zustand, der emotional dem von Kindern ähnelt. Dann muss man sie womöglich - statt sie in die Schranken zu verweisen - aus der Öffentlichkeit in eine geschützte Umgebung (etwa ein Behandlungszimmer) bringen, um die Situation zu entschärfen.

Wichtig in solchen Situationen ist empathische Souveränität - auch wenn das mitunter schwer fällt. Detaildiskus- sionen sind dann oft nicht sinnvoll, denn das Erleben des Betroffenen kann für andere schwer nachvollziehbar sein. Das Dagegenreden steigert die Not des Patienten noch weiter, weil er sich jetzt nicht verstanden fühlt. So werden ungute Gefühle wie Angst und Einsamkeit noch verstärkt.

Daneben gibt es natürlich Patienten aus anderen Kulturkreisen, die oft falsche Erwartungen an die Praxis haben. Diese können aber korrigiert werden.

In der Rubrik „sprechstunde“ geht es um den Umgang mit Asthmapatienten im DMP und um das frühzeitige Erkennen eines Schlaganfalls. Und in der „praxisorganisation“ werden die Rahmenbedingungen zur Verordnung häuslicher Krankenpflege noch einmal Punkt für Punkt erklärt.

Dr. Reinhard Merz

\section{„info praxisteam“ im Web}

Unser MFA-Magazin erscheint viermal jährlich. Alle Beiträge sind unter

www.info-praxisteam.de

auch im Internet abrufbar und können direkt kommentiert werden.

Auch für mobile Endgeräte wie Smartphones oder Tablets ist „info praxisteam“ verfügbar. Die App wird sowohl für iOS von Apple als auch für Geräte mit Android-Plattform angeboten. Mehr darüber, wie man die App beziehen kann, erfahren Sie auf der oben angegebenen Website.

Zu den Beiträgen im Heft gibt es von der Redaktion ausgesuchte Verweise auf weiterführende Informationen im Internet. Viele davon sind auch für Sie als Arzt interessant.

Sie erreichen uns per E-Mail unter

redaktion@info-praxisteam.de 